Article

\title{
Enhancing the Sensitivity of Nanoplasmonic Thin Films for Ethanol Vapor Detection
}

\author{
Marco S. Rodrigues $\left(\mathbb{D}\right.$, Joel Borges * ${ }^{\mathbb{D}}$ and Filipe Vaz \\ Centro de Física, Universidade do Minho, Campus de Gualtar, 4710-057 Braga, Portugal; \\ mprodrigues@fisica.uminho.pt (M.S.R.); fvaz@fisica.uminho.pt (F.V.) \\ * Correspondence: joelborges@fisica.uminho.pt or joelborges22@gmail.com
}

Received: 16 January 2020; Accepted: 13 February 2020; Published: 14 February 2020

check for updates

\begin{abstract}
Nanoplasmonic thin films, composed of noble metal nanoparticles (gold) embedded in an oxide matrix, have been a subject of considerable interest for Localized Surface Plasmon Resonance (LSPR) sensing. Ethanol is one of the promising materials for fuel cells, and there is an urgent need of a new generation of safe optical sensors for its detection. In this work, we propose the development of sensitive plasmonic platforms to detect molecular analytes (ethanol) through changes of the LSPR band. The thin films were deposited by sputtering followed by a heat treatment to promote the growth of the gold nanoparticles. To enhance the sensitivity of the thin films and the signal-to-noise ratio (SNR) of the transmittance-LSPR sensing system, physical plasma etching was used, resulting in a six-fold increase of the exposed gold nanoparticle area. The transmittance signal at the LSPR peak position increased nine-fold after plasma treatment, and the quality of the signal increased six times (SNR up to 16.5). The optimized thin films seem to be promising candidates to be used for ethanol vapor detection. This conclusion is based not only on the current sensitivity response but also on its enhancement resulting from the optimization routines of thin films' architectures, which are still under investigation.
\end{abstract}

Keywords: thin films; gold nanoparticles; titanium dioxide; sputtering; plasma etching; plasmonic sensing; optical transmittance change; optical signal quality

\section{Introduction}

Thin films incorporating gold $(\mathrm{Au})$ or silver $(\mathrm{Ag})$ nanoparticles and exhibiting plasmonic behavior have received significant attention over the past years due to their high sensitivity to different dielectric environments [1,2]. Several microstructures can be achieved when different nanoparticles are embedded in different host dielectric matrixes, making it possible to tailor the Localized Surface Plasmon Resonance (LSPR) extinction band [3-10]. Thus, the range of possible applications for these nanomaterials is wide, from decorative colored coatings [11] to the detection of single molecules $[12,13]$. These molecules may be detected as shifts of the LSPR band [14] when they are adsorbed near the nanoparticles, since they produce a slight change in the refractive index. Due to the short decay length (exponential decay of the evanescent field with the increasing distance from the surface of the plasmonic metal nanoparticle) of localized surface plasmons [15-20], the sensing zone of these LSPR sensors is highly localized near the nanoparticle, limiting the size of the sensing volume to around $30 \mathrm{~nm}$ from the surface of the nanoparticle [21,22].

A titanium dioxide $\left(\mathrm{TiO}_{2}\right)$ matrix and noble metal nanoparticles ( $\mathrm{Au}$ or/and $\mathrm{Ag}$ ) may be used independently in sensing applications [23-30], but it is known that their sensing capabilities are enhanced when they are combined [31]. Moreover, by using a mixture of these materials, the mechanical stability of $\mathrm{TiO}_{2}$ is combined with the plasmonic sensing properties of $\mathrm{Au}$. These plasmonic thin films, consisting of noble metal nanoparticles embedded in an oxide matrix, have proven to be mechanically 
strong materials [32] for applications that require contact with external elements, such as decorative coatings and sensors. While for decorative applications these type of thin films are usually prepared with a thickness above $400 \mathrm{~nm}$, the thickness of LSPR thin film sensors should be below $100 \mathrm{~nm}$ [33], so that most nanoparticles embedded in the film can be influenced by the presence of analyte molecules. To enhance the sensing capabilities, a physical [5,10] or chemical [34] etching process can be employed, thus making the nanoparticles semi-exposed, but still anchored in the oxide matrix.

Ethanol is an important volatile organic compound that has been recently investigated for the production of fuel cells [35-37], as a substitute of hydrogen and methanol, which are more toxic and dangerous to transport. Moreover, the production of ethanol from biomass is an efficient process [38]. It is thus important to have a new type of optical ethanol vapor sensor that can be stable at high temperature and that can be used inside the channels that feed an engine working with an ethanol fuel cell. Most used sensors rely on electrical measurements [39-42], so the huge advantage of an optical sensor is that there is no need for electrical wiring inside the conduit, thus reducing the risk of ignition and explosion. A visible light beam can simply enter the conduit through an optically transparent window, interact with the plasmonic thin film, then leave through another transparent window, and finally interact with a detector.

In this work, composite $\mathrm{Au}-\mathrm{TiO}_{2}$ thin films were prepared in a three-step, fully physical and straightforward process with no by-products, involving: i) reactive DC magnetron sputtering with a Ti-Au target, ii) in-air annealing, and iii) Ar plasma etching. The composition, morphology, and optical response of the thin films were analyzed. Finally, the effect of a surface plasma treatment on the sensitivity of the films against ethanol vapor was studied.

\section{Materials and Methods}

Plasmonic thin films were produced by reactive DC magnetron sputtering using a pure titanium target $\left(200 \times 100 \times 6 \mathrm{~mm}^{3}, 99.99 \%\right.$ purity), with gold pellets (two half disks with $4.5 \mathrm{~mm}$ diameter, $99.9 \%$ purity) incrusted in the erosion track (detailed view in Figure 1a-i), in a custom-made $60 \mathrm{~L}$ vacuum chamber [33]. All depositions were performed after a vacuum of approximately $4 \times 10^{-4} \mathrm{~Pa}$ was reached inside the reactor. During the sputtering process, the atmosphere was composed of a mixture of Ar (flow of $25 \mathrm{sccm}$, partial pressure of $3.8 \times 10^{-1} \mathrm{~Pa}$ ) and $\mathrm{O}_{2}$ (flow of $4.5 \mathrm{sccm}$, partial pressure of $5 \times 10^{-2} \mathrm{~Pa}$ ). The plasma was ignited, using a current density of $100 \mathrm{~A} \cdot \mathrm{m}^{-2}$ for $18 \mathrm{~min}$. The grounded sample holder was used in rotation mode $(5 \mathrm{rpm})$, at $7 \mathrm{~cm}$ from the target. No external heating was used. Glass substrates were used for optical and morphological characterization and for ethanol vapor sensitivity tests. Before all depositions, the surface of the substrates was cleaned by applying a plasma treatment for 15 min using a Low-Pressure Plasma System (Zepto Model with a $40 \mathrm{kHz}$ RF generator, Diener Electronic, Ebhausen, Germany), with a power of $100 \mathrm{~W}$ in an $80 \mathrm{~Pa}$ argon atmosphere.

In a second step, to induce the necessary morphological changes of the Au nanoparticles, needed to tailor the thin films sensitivity, an annealing treatment was performed at $400{ }^{\circ} \mathrm{C}$ for $5 \mathrm{~h}$ in air (Figure 1a-ii). Then, finally, to partially expose the nanoparticles, while keeping them anchored to $\mathrm{TiO}_{2}$, the films were etched using an argon plasma treatment system (Figure 1a-iii) for $1 \mathrm{~h}$, a process optimized in a previous work [10].

The morphological features of the films before and after the plasma treatment were observed by Scanning Electron Microscopy (SEM) using an AURIGA Compact FIB-SEM from ZEISS (Oberkochen, Germany), operated at $5 \mathrm{kV}$. To make the samples conductive, a $0.5 \mathrm{~nm}$ layer of Pt was deposited. The Au nanoparticles, exposed after plasma etching treatment, size distributions (Feret diameter, aspect ratio, and the nearest neighbor), were investigated using SEM micrographs and analyzed in MATLAB (version R2018a, The MathWorks, Inc., Netick, MA, USA).

The composition was characterized by Rutherford backscattering spectrometry (RBS). RBS measurements were made in a chamber with three detectors installed: a standard detector at $140^{\circ}$ and two pin-diode detectors located symmetrically to each other, both at $165^{\circ}$. Spectra were collected for $2 \mathrm{MeV} 4 \mathrm{He}+$. The angles of incidence were $0^{\circ}$ (normal incidence) and $25^{\circ}$. The RBS 
data were analyzed with the IBA DataFurnace NDF v10.0a (CTN, Instituto Superior Técnico, Lisboa, Portugal) [43], double scattering [44], and pileup [45].

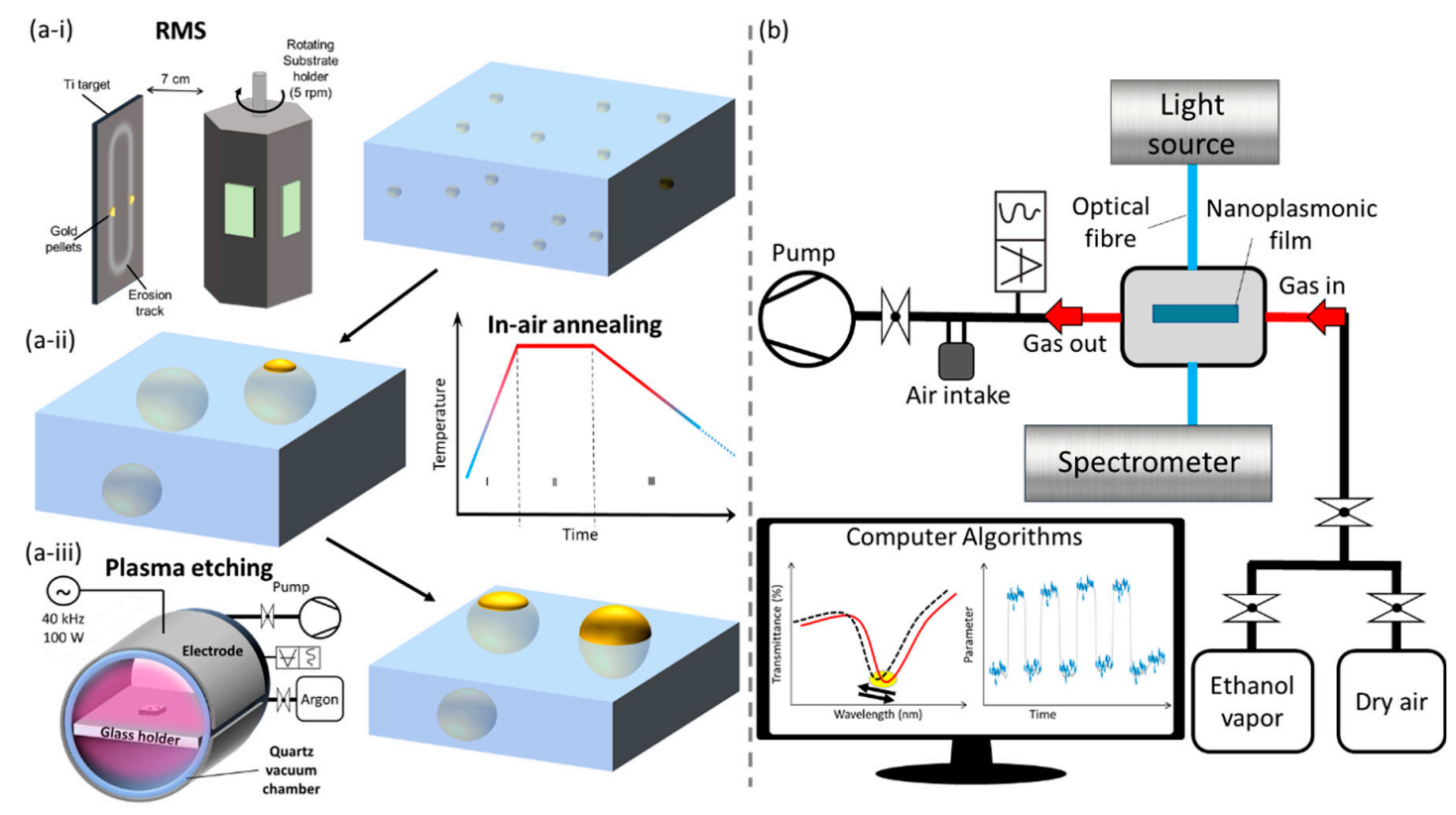

Figure 1. (a) Simplified production methods for the plasmonic thin-film sensors in three steps, (a-i) Reactive Magnetron Sputtering (RMS) showing the target and the sample holder geometry inside the vacuum chamber), (a-ii) in-air annealing process in three phases (I-heating ramp of $5{ }^{\circ} \mathrm{C} / \mathrm{min}$, II-plateau at $400{ }^{\circ} \mathrm{C}$ for $5 \mathrm{~h}$, and III-free cooling), and (a-iii) argon plasma etching process in a Diener Zepto vacuum chamber. (b) Simplified schematics of the optical Transmittance-Localized Surface Plasmon Resonance (T-LSPR) sensing system.

The ethanol vapor sensitivity test was conducted in a custom-made optical system (Figure 1b) that allows transmittance measurements in different atmospheres (T-LSPR sensing system). It consists of a vacuum chamber, a rotary vane pump, several gas inlets, a tungsten light source, and a spectrometer (HR4000, Ocean Optics, Edinburgh, UK). Cycles of a dry-air atmosphere and pure-ethanol atmosphere were then used inside the chamber containing the plasmonic thin film, while measuring the transmittance spectra (Before introducing the test gases, a primary vacuum of $2 \times 10^{2} \mathrm{~Pa}$ was achieved, and each gas was introduced until a pressure of $2.5 \times 10^{4} \mathrm{~Pa}$ was reached. The spectrometer acquisition parameters were set to $4 \mathrm{~ms}$ integration time and an averaging of 500 scans, giving a spectrum every 2 seconds, and for each atmosphere a total number of 60 transmittance spectra were acquired. The transmittance spectra were then analyzed using an algorithm written in MATLAB that calculates the exact position of the LSPR peak (both wavelength and transmittance, by fitting a polynomial function to each spectrum) and the transmittance at several discrete wavelengths. Then, the shifts of these quantities between both atmospheres were estimated, and the signal-to-noise ratio (SNR-ratio between the average shift and the standard deviation) were calculated. Optical Transmittance Change (OTC) was also determined considering the difference between the average transmittance spectra in dry air and the average transmittance spectra in ethanol.

\section{Results and Discussion}

\subsection{Plasmonic Thin Films Characterization}

The chemical analysis of the as-deposited nanocomposite thin films was performed by RBS, and the $\mathrm{Au}$ atomic concentration was found to be of 6 at. \%, dispersed in a nearly stoichiometric $\mathrm{TiO}_{2}$ matrix (30 at.\% of titanium and 64 at.\% of oxygen). The thickness was estimated at 100 nm. To make 
the films even more economically sustainable compared to previous works [10,33], both the thickness and the Au concentration were lowered to a threshold where they maintained a well-defined LSPR extinction band.

To study the effect of plasma treatment on the morphology of the thin film's surface, top-view SEM were acquired, before (Figure 2a-i) and after plasma treatment (Figure 2b-i). As expected, the striking feature that can be extracted from these micrographs is that the visible Au nanoparticles at the film's surface had increased.

$(\mathrm{a}-\mathrm{i})$

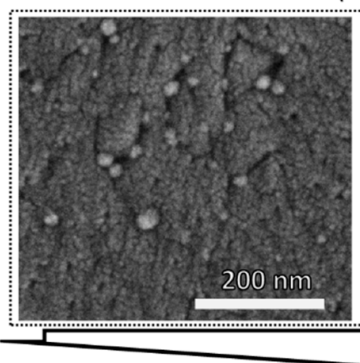

\section{$(-i)$}

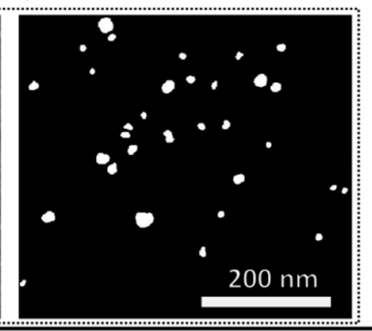

(a-ii)

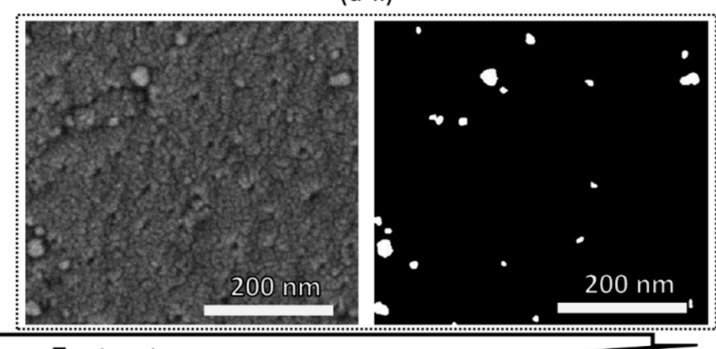

(b-ii)
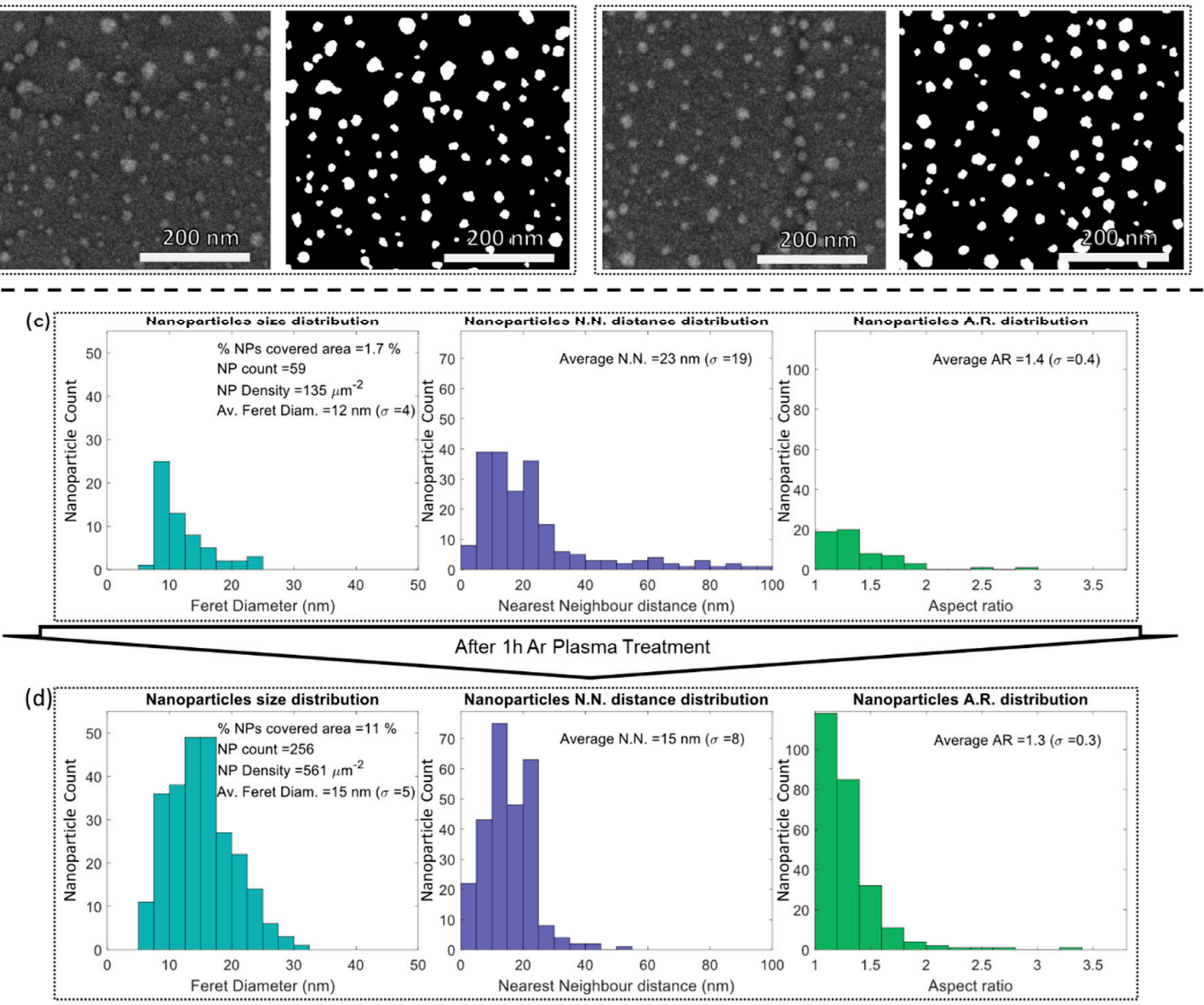

Figure 2. SEM top-view micrographs in two different areas of the film's surface, before (a-i,a-ii) and after (b-i,a-ii) the "uncovering" of the Au nanoparticles by plasma treatment. Statistical analysis of the exposed nanoparticles (size, nearest neighbor, and aspect ratio distributions) before (c) and after (d) plasma treatment. 
After examining the images in MATLAB, nanoparticles size, nearest neighbor, and aspect ratio were depicted in the histograms of Figure 2a-ii and b-ii. After plasma treatment, the nanoparticle count increased four times, and the Au-covered area increased six times, thus reaching a density of 561 nanoparticles/ $\mu \mathrm{m}^{2}$. The average size (Feret diameter) of the nanoparticles increased slightly from 12 to $15 \mathrm{~nm}$, and their distribution became slightly broader. The partial uncovering of the nanoparticles brought new neighbors to the surface, and so the nearest-neighbor distribution became narrower after plasma treatment. As a consequence, the nearest neighbor became much closer, and its average distance changed from 23 to $15 \mathrm{~nm}$. The nanoparticles aspect ratio (AR) distribution became slightly narrower, and the nanoparticles became slightly rounder (AR of 1.3). Thus, after plasma treatment, the resulting surface of the thin films presented rounder nanoparticles with a diameter of $15 \mathrm{~nm}$, separated from each other by $15 \mathrm{~nm}$.

The optical response of the films was also examined before and after Ar plasma treatment (Figure 3). As can be seen from Figure 3a, the transmittance spectra changed slightly, presenting a $1.5 \mathrm{~nm}$ blueshift in the wavelength position of the LSPR peak and a shift around $0.10 \mathrm{pp}$ in the transmittance coordinate (Figure 3b). From the OTC (calculated by subtracting the spectra before and after plasma treatment) of Figure $3 a$, one can conclude that the higher positive change between both spectra occurred around $619 \mathrm{~nm}$, where the transmittance was increased by $0.30 \mathrm{pp}$, and the higher negative change was around $532 \mathrm{~nm}$, with a transmittance decrease of $0.13 \mathrm{pp}$. The blueshift in the LSPR band was also indicated by the positive slope between 532 and $619 \mathrm{~nm}$. This blueshift resulted from an overall response of the thin film due to the exposure of Au nanoparticles, which became in contact with air. Since air has a lower refractive index than the $\mathrm{TiO}_{2}$ matrix (where the nanoparticles were still partially anchored), the effective refractive index of the surrounding media was reduced, which explains the shift of the LSPR band [10].
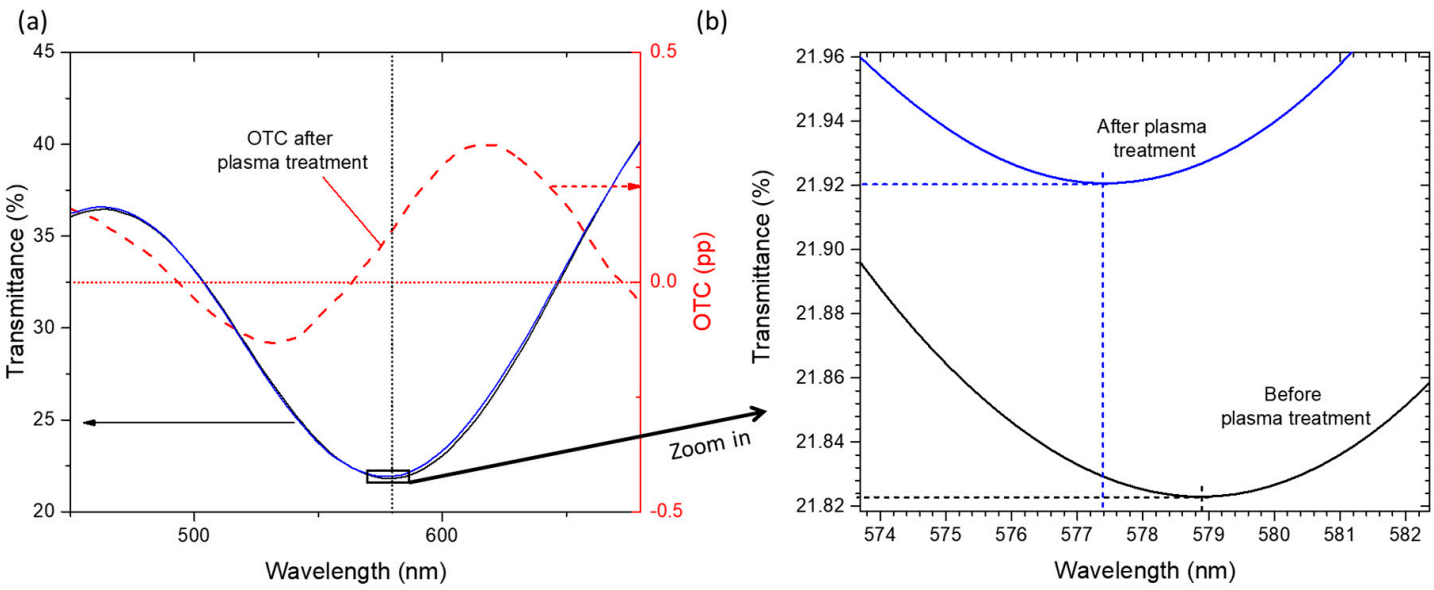

Figure 3. (a) Transmittance of the films before and after plasma treatment, with the resulting Optical Transmittance Change (OTC); (b) Zoom of the spectra showing a blueshift of the LSPR peak of $1.5 \mathrm{~nm}$.

\subsection{Ethanol Vapor Sensitivity}

The room-temperature ethanol vapor sensitivity of the films, before and after plasma treatment, was tested against dry air, by measuring their transmittance spectra in each atmosphere for several cycles, with 60 spectra taken in each cycle (Figure 4), as explained in the experimental section. 


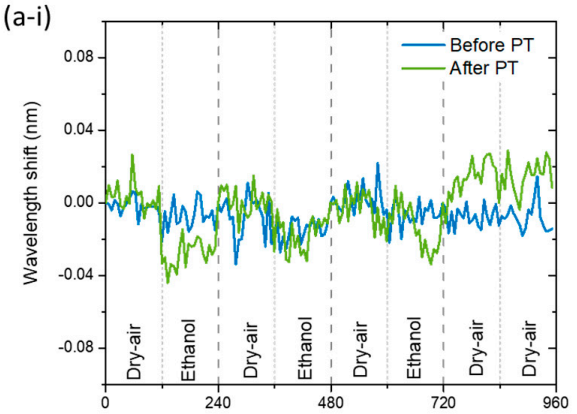

(b-i)

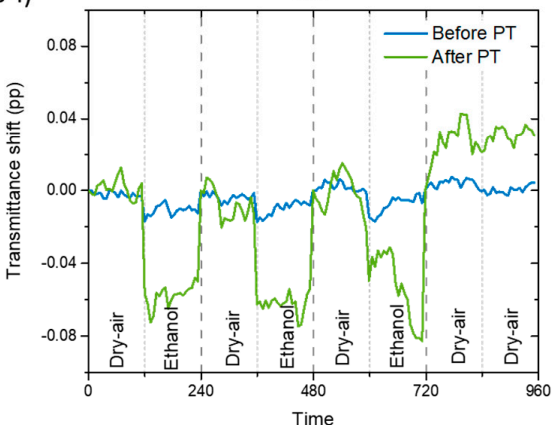

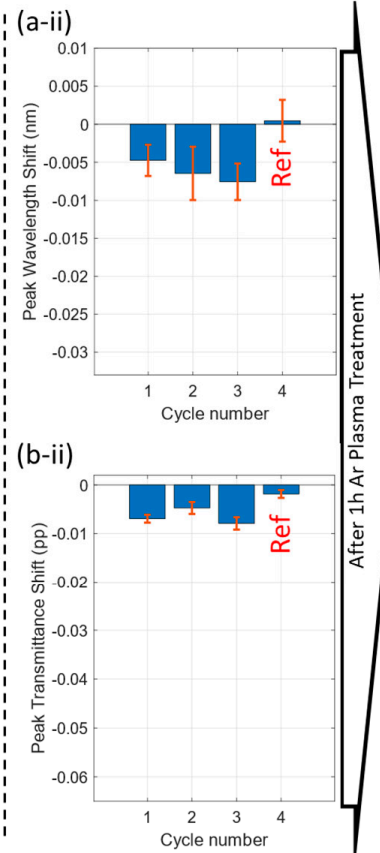

(a-iii)

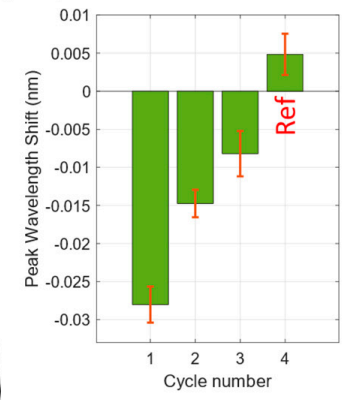

(b-iii)

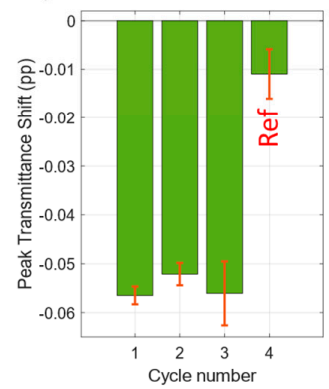

Figure 4. LSPR peak position monitoring of dry-air and ethanol vapor cycles, before (blue) and after (green) $1 \mathrm{~h}$ Ar plasma treatment show (a) the wavelength and (b) the transmittance coordinates shift of the LSPR peak. (a-i,b-i) Over-time measurements. Before plasma treatment, an average wavelength blueshift of only (a-ii) $0.006 \mathrm{~nm}$ gave rise to (a-iii) a three-fold increase corresponding to $0.017 \mathrm{~nm}$, while the transmittance shift was increased from (b-ii) 0.007 pp to (b-iii) 0.055 pp (nine-fold increase).

LSPR peak shifts were measured for both wavelength (Figure 4a) and transmittance (Figure $4 b$ ) coordinates. The cycles between each gas were perfectly visible over time (Figure $4 a-i, b-i)$, and it is obvious that, after plasma treatment, the response of the plasmonic thin films was enhanced, especially in the transmittance coordinate. The LSPR peak wavelength coordinate absolute shift was enhanced from $0.006 \mathrm{~nm}$ (Figure 4a-ii) to $0.017 \mathrm{~nm}$ (Figure 4a-iii), corresponding to a three-fold increase, and the transmittance absolute shift was also enhanced from $0.007 \mathrm{pp}$ (Figure $4 \mathrm{~b}$-ii) to $0.055 \mathrm{pp}$ (Figure $4 \mathrm{~b}$-iii), thus resulting in a nine-fold increase. The reference cycle (last cycle in the graphs, marked as Ref in red), where the measurement was made with two atmospheres of dry air only, was always significantly different from the test cycles (ethanol and dry air), and no change was measured, thus confirming the different response of the plasmonic thin films to ethanol and dry-air atmospheres. From these results, one can conclude that only an adsorption process occurred [46,47], since the plasmonic thin films recovered in each cycle. As demonstrated in this work and in other related works [5,10], the argon plasma treatment caused a small etching to the film's surface, exposing the nanoparticles. Several cycles were done, and the ethanol vapor sensitivity was maintained, but other measurements are required to confirm long-term stability.

For a detailed analysis of the full visible spectra, when the films were exposed to dry air and ethanol, the OTC was calculated before (Figure 5a-i) and after (Figure 5a-ii) plasma treatment. For both thin films, the higher transmittance change (decrease in transmittance) occurred near $450 \mathrm{~nm}$, and not at the LSPR peak position $(\sim 578 \mathrm{~nm})$, so the transmittance shift was analyzed at $450 \mathrm{~nm}$ (Figure $5 \mathrm{~b}-\mathrm{i}, \mathrm{b}-\mathrm{ii}$ ). Similarly, a seven-fold signal increase was achieved with plasma treatment, from $0.018 \mathrm{pp}$ to $0.123 \mathrm{pp}$. 

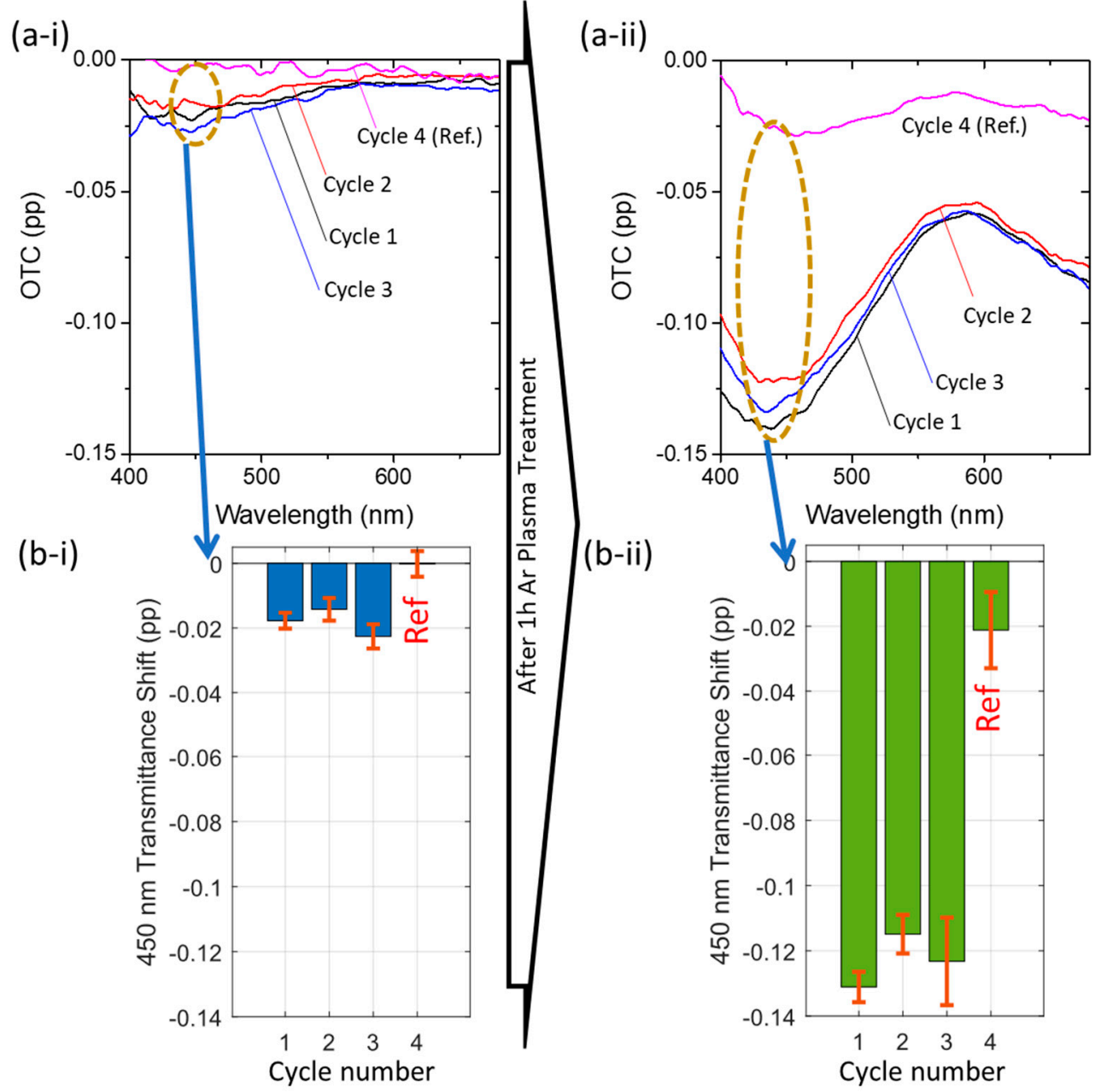

Figure 5. (a) Optical transmittance change of the full spectra and (b) transmittance shift at $450 \mathrm{~nm}$, between dry-air and ethanol atmospheres, before (a-i,b-i) and after (a-ii,b-ii) plasma treatment. The transmittance shift at $450 \mathrm{~nm}$ was estimated to increase from $0.018 \mathrm{pp}$ to $0.123 \mathrm{pp}$, a seven-fold increase.

To evaluate the signal quality, the SNR was calculated for each case (see Figure 6). Regarding the LSPR peak wavelength coordinate shift, the SNR was always below the detection limit (SNR < 3) [48]. Therefore, although the LSPR peak wavelength signal was enhanced, the quality of the signal remained practically unchanged after plasma treatment. Nonetheless, considering the transmittance coordinates at the LSPR peak, the SNR was significantly improved from 2.8 to 16.5 (a six-fold increase), making this parameter more suitable for a good-quality measurement. For the transmittance shift at $450 \mathrm{~nm}$, the SNR was also improved, increasing from 4.1 (before plasma treatment) to 15.4 (after plasma treatment), a little bit less than the transmittance shift in the LSPR peak position. Thus, although the signal at $450 \mathrm{~nm}$ was higher when compared to the transmittance at the LSPR peak position (0.123 pp at $450 \mathrm{~nm}$ and $0.055 \mathrm{pp}$ at the LSPR peak position), the latter was more stable, thus giving a better SNR. 


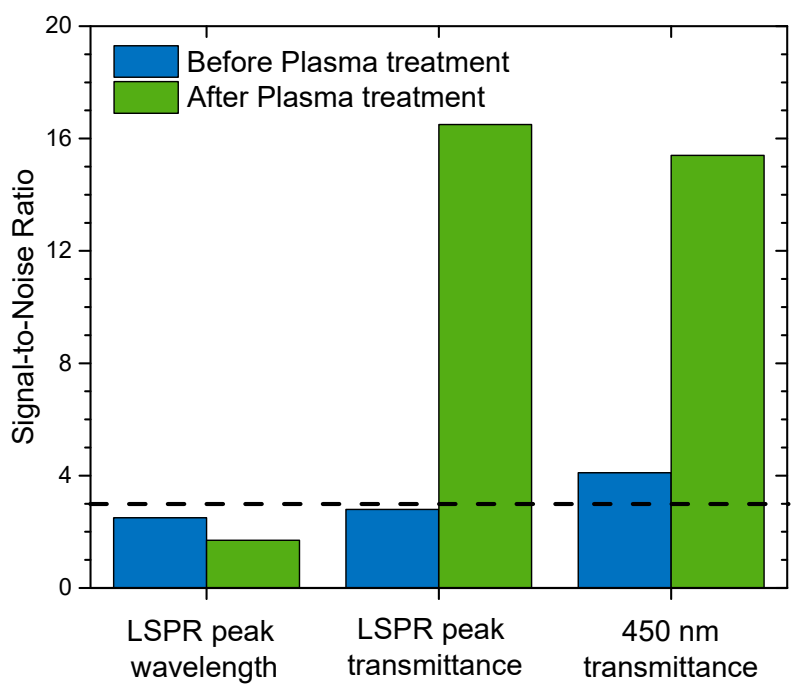

Figure 6. Signal-to-noise ratio (SNR) of the several measured signals, before and after Ar plasma treatment. The dashed line sets the threshold of the minimum SNR needed for detection.

\section{Conclusions}

In this work, a plasmonic thin film composed of Au nanoparticles dispersed in a $\mathrm{TiO}_{2}$ matrix was optimized to be sensitive to ethanol vapor. An innovative preparation method was used, consisting of three main steps, namely, i) reactive magnetron sputtering, ii) in-air thermal treatment, and iii) low-pressure Ar plasma etching. The last step allowed the nanoparticles to become partially exposed at the film's surface, favoring the interaction with the analyte molecules (ethanol), thus resulting in improved film's sensitivity. This sensitivity enhancement resulted in a signal that was increased by a factor of 9 in the LSPR transmittance coordinate and a factor of 7 in the transmittance measured at $450 \mathrm{~nm}$. There seems to be a correlation between the SNR and the exposed Au area, since they both had a six-fold enhancement. The SNR results confirmed that the transmittance measurements at the LSPR peak $(S N R=16.5)$ and at $450 \mathrm{~nm}(\mathrm{SNR}=15.4)$ can be used as detection signals of the sensor.

Author Contributions: Conceptualization, M.S.R. and J.B.; methodology, M.S.R. and J.B.; software, M.S.R.; validation, F.V. and J.B.; formal analysis, M.S.R.; investigation, M.S.R.; resources, F.V. and J.B; data curation, M.S.R. and J.B.; writing-original draft preparation, M.S.R. and J.B.; writing-review and editing, J.B. and F.V.; visualization, M.S.R. and J.B; supervision, F.V. and J.B.; project administration, F.V.; funding acquisition, J.B. and F.V. All authors have read and agreed to the published version of the manuscript.

Funding: This research was funded by the Portuguese Foundation for Science and Technology (FCT) in the framework of the Strategic Funding UID/FIS/04650/2019 and by the projects NANOSENSING: POCI-01-0145-FEDER-016902, with FCT reference PTDC/FIS-NAN/1154/2014, and NANO4BIO: POCI-01-0145-FEDER-032299, with FCT reference PTDC/FIS-MAC/32299/2017.

Acknowledgments: Marco S. Rodrigues acknowledges FCT for his PhD Scholarship, SFRH/BD/118684/2016. Joel Borges acknowledges FCT for his Researcher Contract from project NANO4BIO.

Conflicts of Interest: The authors declare no conflict of interest.

\section{References}

1. Stockman, M.I. Nanoplasmonics: The physics behind the applications. Phys. Today 2011, 64, 39. [CrossRef]

2. Himmelhaus, M.; Krishnamoorthy, S.; Francois, A. Optical Sensors Based on Whispering Gallery Modes in Fluorescent Microbeads: Response to Specific Interactions. Sensors 2010, 10, 6257-6274. [CrossRef]

3. Domingues, R.P.; Rodrigues, M.S.; Lopes, C.; Pedrosa, P.; Alves, E.; Barradas, N.P.; Borges, J.; Vaz, F. Thin films composed of metal nanoparticles $(\mathrm{Au}, \mathrm{Ag}, \mathrm{Cu})$ dispersed in $\mathrm{AlN}$ : The influence of composition and thermal annealing on the structure and plasmonic response. Thin Solid Films 2019, 676, 12-25. [CrossRef] 
4. Proença, M.; Borges, J.; Rodrigues, M.S.; Meira, D.I.; Sampaio, P.; Dias, J.P.; Pedrosa, P.; Martin, N.; Bundaleski, N.; Teodoro, O.M.N.D.; et al. Nanocomposite thin films based on Au-Ag nanoparticles embedded in a $\mathrm{CuO}$ matrix for localized surface plasmon resonance sensing. Appl. Surf. Sci. 2019, 484, 152-168. [CrossRef]

5. Meira, D.I.; Domingues, R.P.; Rodrigues, M.S.; Alves, E.; Barradas, N.P.; Borges, J.; Vaz, F. Thin films of $\mathrm{Au}-\mathrm{Al}_{2} \mathrm{O}_{3}$ for plasmonic sensing. Appl. Surf. Sci. 2020, 500, 144035. [CrossRef]

6. Ghidelli, M.; Mascaretti, L.; Bricchi, B.R.; Zapelli, A.; Russo, V.; Casari, C.S.; Li Bassi, A. Engineering plasmonic nanostructured surfaces by pulsed laser deposition. Appl. Surf. Sci. 2018, 434, 1064-1073. [CrossRef]

7. Dewasi, A.; Arya, M.; Mitra, A. Plasmon mediated near zero-reflection of $\mathrm{TiO}_{2} /$ Ag-nanoislands/Si multilayer structure. Mater. Res. Express 2019, 6, 85030. [CrossRef]

8. Li, G.; Liu, S.; Piao, Y.; Jia, B.; Yuan, Y.; Wang, Q. Joint improvement of conductivity and Seebeck coefficient in the ZnO:Al thermoelectric films by tuning the diffusion of Au layer. Mater. Des. 2018, 154, 41-50. [CrossRef]

9. Bricchi, B.R.; Ghidelli, M.; Mascaretti, L.; Zapelli, A.; Russo, V.; Casari, C.S.; Terraneo, G.; Alessandri, I.; Ducati, C.; Li Bassi, A. Integration of plasmonic $\mathrm{Au}$ nanoparticles in $\mathrm{TiO}_{2}$ hierarchical structures in a single-step pulsed laser co-deposition. Mater. Des. 2018, 156, 311-319. [CrossRef]

10. Rodrigues, M.S.; Costa, D.; Domingues, R.P.; Apreutesei, M.; Pedrosa, P.; Martin, N.; Correlo, V.M.; Reis, R.L.; Alves, E.; Barradas, N.P.; et al. Optimization of nanocomposite $\mathrm{Au} / \mathrm{TiO}_{2}$ thin films towards LSPR optical-sensing. Appl. Surf. Sci. 2018, 438, 74-83. [CrossRef]

11. Song, M.; Wang, D.; Peana, S.; Choudhury, S.; Nyga, P.; Kudyshev, Z.A.; Yu, H.; Boltasseva, A.; Shalaev, V.M.; Kildishev, A. V Colors with plasmonic nanostructures: A full-spectrum review. Appl. Phys. Rev. 2019, 6, 41308. [CrossRef]

12. Cappi, G.; Spiga, F.M.; Moncada, Y.; Ferretti, A.; Beyeler, M.; Bianchessi, M.; Decosterd, L.; Buclin, T.; Guiducci, C. Label-Free Detection of Tobramycin in Serum by Transmission-Localized Surface Plasmon Resonance. Anal. Chem. 2015, 87, 5278-5285. [CrossRef]

13. Ghodselahi, T.; Zahrabi, H.; Saani, M.H.; Vesaghi, M.A. CO Gas Sensor Properties of Cu@CuO Core-Shell Nanoparticles Based on Localized Surface Plasmon Resonance. J. Phys. Chem. C 2011, 115, 22126-22130. [CrossRef]

14. Willets, K.A.; Van Duyne, R.P. Localized Surface Plasmon Resonance Spectroscopy and Sensing. Annu. Rev. Phys. Chem. 2007, 58, 267-297. [CrossRef]

15. Sepúlveda, B.; Angelomé, P.C.; Lechuga, L.M.; Liz-Marzán, L.M.; Today, N.; Angelom, P.C. LSPR-based nanobiosensors. Nano Today 2009, 4, 244-251. [CrossRef]

16. Lopez, G.A.; Estevez, M.C.; Soler, M.; Lechuga, L.M. Recent advances in nanoplasmonic biosensors: Applications and lab-on-a-chip integration. Nanophotonics 2017, 6, 123-136. [CrossRef]

17. Raphael, M.P.; Christodoulides, J.A.; Mulvaney, S.P.; Miller, M.M.; Long, J.P.; Byers, J.M. A new methodology for quantitative LSPR biosensing and imaging. Anal. Chem. 2012, 84, 1367-1373. [CrossRef]

18. Willett, D.R.; Chumanov, G. LSPR Sensor Combining Sharp Resonance and Differential Optical Measurements. Plasmonics 2014, 9, 1391-1396. [CrossRef]

19. Kedem, O.; Vaskevich, A.; Rubinstein, I. Critical Issues in Localized Plasmon Sensing. J. Phys. Chem. C 2014, 118, 8227-8244. [CrossRef]

20. Guo, L.; Jackman, J.A.; Yang, H.H.; Chen, P.; Cho, N.J.; Kim, D.H. Strategies for enhancing the sensitivity of plasmonic nanosensors. Nano Today 2015, 10, 213-239. [CrossRef]

21. Zalyubovskiy, S.J.; Bogdanova, M.; Deinega, A.; Lozovik, Y.; Pris, A.D.; An, K.H.; Hall, W.P.; Potyrailo, R.A. Theoretical limit of localized surface plasmon resonance sensitivity to local refractive index change and its comparison to conventional surface plasmon resonance sensor. J. Opt. Soc. Am. A 2012, 29, 994. [CrossRef]

22. Ozhikandathil, J.; Packirisamy, M. Simulation and Implementation of a Morphology-Tuned Gold Nano-Islands Integrated Plasmonic Sensor. Sensors 2014, 14, 10497-10513. [CrossRef]

23. Maolanon, R.; Wongwiriyapan, W.; Pratontep, S. $\mathrm{TiO}_{2} / \mathrm{Pt} / \mathrm{TiO}_{2}$ Sandwich Nanostructures: Towards Alcohol Sensing and UV Irradiation-Assisted Recovery. J. Chem. 2017, 2017. [CrossRef]

24. Li, X.; Zhao, Y.; Wang, X.; Wang, J.; Gaskov, A.M.; Akbar, S.A. Reduced graphene oxide (rGO) decorated $\mathrm{TiO}_{2}$ microspheres for selective room-temperature gas sensors. Sensors Actuators B Chem. 2016, 230, 330-336. [CrossRef] 
25. Castillero, P.; Roales, J.; Lopes-Costa, T.; Sánchez-Valencia, J.; Barranco, A.; González-Elipe, A.; Pedrosa, J. Optical Gas Sensing of Ammonia and Amines Based on Protonated Porphyrin/ $\mathrm{TiO}_{2}$ Composite Thin Films. Sensors 2016, 17, 24. [CrossRef]

26. Ma, W.; Yang, H.; Wang, W.; Gao, P.; Yao, J. Ethanol vapor sensing properties of triangular silver nanostructures based on localized surface plasmon resonance. Sensors (Basel) 2011, 11, 8643-8653. [CrossRef]

27. Bonyár, A.; Csarnovics, I.; Veres, M.; Himics, L.; Csik, A.; Kámán, J.; Balázs, L.; Kökényesi, S. Investigation of the performance of thermally generated gold nanoislands for LSPR and SERS applications. Sensors Actuators B Chem. 2018, 255, 433-439. [CrossRef]

28. Paul, D.; Dutta, S.; Biswas, R. LSPR enhanced gasoline sensing with a U-bent optical fiber. J. Phys. D Appl. Phys. 2016, 49, 305104. [CrossRef]

29. Soeda, T.; Yang, Z.; Xiofan, Z.; Sassa, F.; Tomiura, Y.; Hayashi, K. Two dimensional LSPR gas sensor with $\mathrm{Au} / \mathrm{Ag}$ core-shell structure. In Proceedings of the 2019 IEEE International Symposium on Olfaction and Electronic Nose (ISOEN), Fukuoka, Japan, 26-29 May 2019; pp. 1-3.

30. Yang, Z.; Sassa, F.; Hayashi, K. A robot equipped with a high-speed LSPR gas sensor module for collecting spatial odor information from on-ground invisible odor sources. ACS Sensors 2018, 3, 1174-1181. [CrossRef]

31. Samransuksamer, B.; Horprathum, M.; Eiamchai, P.; Patthanasettakul, V.; Wisitsoraat, A.; Chananonnawathorn, C.; Phokharatkul, D.; Chindaudom, P.; Jutarosaga, T.; Rakreungdet, W.; et al. Decoration of Gold Nanoparticles on $\mathrm{TiO}_{2}$ Thin Films for Enhanced Response of Ethanol Gas Sensors. Adv. Mater. Res. 2014, 979, 251-254. [CrossRef]

32. Rodrigues, M.S.; Borges, J.; Gabor, C.; Munteanu, D.; Apreutesei, M.; Steyer, P.; Lopes, C.; Pedrosa, P.; Alves, E.; Barradas, N.P.; et al. Functional behaviour of $\mathrm{TiO}_{2}$ films doped with noble metals. Surf. Eng. 2015, 32, 554-561. [CrossRef]

33. Rodrigues, M.S.; Borges, J.; Proença, M.; Pedrosa, P.; Martin, N.; Romanyuk, K.; Kholkin, A.L.; Vaz, F. Nanoplasmonic response of porous $\mathrm{Au}-\mathrm{TiO}_{2}$ thin films prepared by oblique angle deposition. Nanotechnology 2019, 30, 225701. [CrossRef] [PubMed]

34. Pedrueza, E.; Sancho-Parramon, J.; Bosch, S.; Valdés, J.L.; Martinez-Pastor, J.P. Plasmonic layers based on Au-nanoparticle-doped $\mathrm{TiO}_{2}$ for optoelectronics: structural and optical properties. Nanotechnology 2013, 24, 65202. [CrossRef]

35. An, L.; Zhao, T.S.; Li, Y.S. Carbon-neutral sustainable energy technology: Direct ethanol fuel cells. Renew. Sustain. Energy Rev. 2015, 50, 1462-1468. [CrossRef]

36. Vello, T.P.; de Oliveira, R.F.; Silva, G.O.; de Camargo, D.H.S.; Bufon, C.C.B. A simple capacitive method to evaluate ethanol fuel samples. Sci. Rep. 2017, 7, 43432. [CrossRef]

37. Liang, Z.; Song, L.; Deng, S.; Zhu, Y.; Stavitski, E.; Adzic, R.R.; Chen, J.; Wang, J.X. Direct 12-Electron Oxidation of Ethanol on a Ternary Au(core)-PtIr(Shell) Electrocatalyst. J. Am. Chem. Soc. 2019, 141,9629-9636. [CrossRef]

38. Dalena, F.; Senatore, A.; Iulianelli, A.; Di Paola, L.; Basile, M.; Basile, A. Chapter 2-Ethanol From Biomass: Future and Perspectives. In; Basile, A. Ethanol Sci. Eng. 2019, 25-59. [CrossRef]

39. Bahraminejad, B.; Basri, S.; Isa, M.; Hambli, Z. Real-Time Gas Identification by Analyzing the Transient Response of Capillary-Attached Conductive Gas Sensor. Sensors 2010, 10, 5359-5377. [CrossRef]

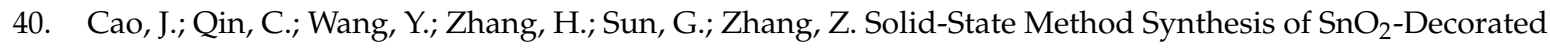
g- $\mathrm{C}_{3} \mathrm{~N}_{4}$ Nanocomposites with Enhanced Gas-Sensing Property to Ethanol. Materials 2017, 10, 604. [CrossRef]

41. Li, Z.; Yi, J. Enhanced ethanol sensing of Ni-doped $\mathrm{SnO}_{2}$ hollow spheres synthesized by a one-pot hydrothermal method. Sensors Actuators B Chem. 2017, 243, 96-103. [CrossRef]

42. Singh, G.; Virpal; Singh, R.C. Highly sensitive gas sensor based on Er-doped $\mathrm{SnO}_{2}$ nanostructures and its temperature dependent selectivity towards hydrogen and ethanol. Sens. Actuators B Chem. 2019, 282, 373-383. [CrossRef]

43. Barradas, N.P.; Jeynes, C.; Jackson, S.M. RBS/Simulated annealing analysis of buried SiCOx layers formed by implantation of $\mathrm{O}$ into cubic silicon carbide. Nucl. Instruments Methods Phys. Res. Sect. B 1998, 136-138, 1168-1171. [CrossRef]

44. Barradas, N.P.; Pascual-Izarra, C. Double scattering in RBS analysis of PtSi thin films on Si. Nucl. Instruments Methods Phys. Res. Sect. B 2005, 228, 378-382. [CrossRef]

45. Barradas, N.P.; Reis, M.A. Accurate calculation of pileup effects in PIXE spectra from first principles. X-Ray Spectrom. 2006, 35, 232-237. [CrossRef] 
46. Abokifa, A.A.; Haddad, K.; Fortner, J.; Lo, C.S.; Biswas, P. Sensing mechanism of ethanol and acetone at room temperature by $\mathrm{SnO}_{2}$ nano-columns synthesized by aerosol routes: theoretical calculations compared to experimental results. J. Mater. Chem. A 2018, 6, 2053-2066. [CrossRef]

47. Al-Hashem, M.; Akbar, S.; Morris, P. Role of Oxygen Vacancies in Nanostructured Metal-Oxide Gas Sensors: A Review. Sensors Actuators B Chem. 2019, 301, 126845. [CrossRef]

48. Djurić, Z.; Jokić, I.; Milovanović, G. Signal-to-Noise Ratio in Adsorption-Based Microfluidic Bio/Chemical Sensors. Procedia Eng. 2016, 168, 642-645. [CrossRef]

(C) 2020 by the authors. Licensee MDPI, Basel, Switzerland. This article is an open access article distributed under the terms and conditions of the Creative Commons Attribution (CC BY) license (http://creativecommons.org/licenses/by/4.0/). 